\title{
By-Election to the PEC of the British Dental Association
}

Nominations are sought for the following seat on the Principal

Executive Committee (PEC):

\section{UK-wide (one seat)}

The PEC has overall responsibility for the control and direction of the policy and affairs of the BDA and its members are the directors of the Association.

There are 15 members on the PEC. Each will have a share of overall responsibilities, and typically this will require:

- Attendance at all meetings of the PEC - around five a year, but maybe more when business demands

- Attendance at own country council meetings - usually three a year

- Attendance at UK Council meetings - around two a year

- Sit on 1-2 sub committees/issue specific forums

- Attend general meetings of the Association.

It is anticipated that the approximate time commitment for a member of the PEC will be 20 days per year, with an annual remuneration of $£ 15,000$.

\section{Term of office}

This shall be until December 2023, with the opportunity to stand for a further full three-year term of office at that point.

\section{Induction, support and training}

Membership of the PEC carries significant organisational and legal responsibilities. There is an induction programme for those elected, and ongoing training. Members will also have advice and support from the Chief Executive and the wider BDA Team.

\section{Next meetings of the PEC}

Meetings of the PEC in 2021 are currently scheduled for:

Wednesday 8 September,

Wednesday 1 December

Nomination forms must be submitted online by 17.00 Friday 11 June 2021. A link to the online nomination portal can be found at www.bda.org/elections.

For more information about the elections to the PEC or the role of a PEC member please contact the BDA's Election Manager Stephen Skelton on 02075634141 or stephen.skelton@bda.org.

\section{a BDA AGM}

\section{1}

The BDA North Western Branch AGM will be held online on Thursday 1 July 2021 at 19:00.
Please ensure you register your interest in attending at www.bda. org/bse in order to receive the link to access the AGM or email branchsectionevents@bda.org. 